\title{
Growth Hormone (GH), Insulin-like Growth Factor I (IGF-I), GH-Binding Protein (GHBP) and Nutritional Improvement in a Girl with Deprivation Syndrome
}

Reiko Horikawa, Toshiaki Tanaka, Noriyuki Katsumata, Mari Satoh, Masayuki Kokaji, Sachiko Kitanaka, Ayako Tanae and Itsuro Hibi

Department of Endocrinology \& Metabolism, National Children's Medical Research Center (RH, TT, NK, MS), Division of Endocrinology \& Metabolism, National Children's Hospital (MK, SK, AT, IH), Tokyo, Japan

\section{Introduction}

Emotional deprivation is associated with severe growth retardation. Transient pituitary dysfunction including growth hormone $(\mathrm{GH})$ insufficiency is thought to be one of the causes of growth failure (1-3). Such hormonal dysfunction is restored during the period of catchup growth (4). On the other hand, GH treatment is reported to be ineffective in deprivation syndrome (5), indicating that there is tissue resistance to $\mathrm{GH}$. To investigate the cause of growth failure in children with deprivation syndrome, we studied the changes in serum GH-binding protein (GHBP) levels.

\section{Case Report}

A girl aged 3 years 4 months presented with growth retardation which had first been noted at the age of six months. Her father was a 34 years old white-collar worker, $160 \mathrm{~cm}$ tall and $60 \mathrm{~kg}$ in weight. The mother was 25 years old, $158 \mathrm{~cm}$ tall and $45 \mathrm{~kg}$ in weight. Her brother was 4 years 3 months. His height and weight

Correspondence: Dr. Reiko Horikawa, Department of Endocrinology \& Metabolism, National Children's Medical Research Center, 3-35-31, Taishido, Setagaya-ku, Tokyo 154 Japan were within the normal ranges. No familial diseases were apparent. The patient was born normally at 37 weeks gestation. Birth weight was $2,500 \mathrm{~g}$ and length was $48 \mathrm{~cm}$. No asphyxia had been observed. Her development was normal but she did not walk till 18 months. She grew normally until 6 months of age although the intake of milk was poor in the early newborn period. Weight gain was poor from 6 months of age except during a one-month admission to another hospital for growth failure. She had frequent loose stools containing undigested food. She was admitted to our hospital for investigation of growth failure. Physical findings on admission were: body weight $6.5 \mathrm{~kg}$ (-4.7 SD); body length $69.4 \mathrm{~cm}$ (-7.3 SD), percent overweight for height $19.4 \%$. Her face was expressionless, the skin was atrophic and dry with hypertrichosis. There was no purpura. The abdomen was distended and hepatomegaly of 7 $\mathrm{cm}$ was detected. The bone age showed a $\mathbf{1 . 5}$ years delay. In laboratory investigations, anemia, hypoproteinemia and liver dysfunction were found. Endocrine results were as follows: insulin-like growth factor I (IGF-I) $21 \mathrm{ng} / \mathrm{mL}$, luteinizing hormone (LH) $0.03 \mathrm{mIU} / \mathrm{mL}$, follicle stimulating hormone (FSH) $0.78 \mathrm{mIU} / \mathrm{mL}$, 3,5,3'-triiodothyronine $\left(\mathrm{T}_{3}\right) 1.6 \mathrm{ng} / \mathrm{mL}$, thyroxine 


\section{Horikawa et al.}

( $\left.\mathrm{T}_{4}\right) 6.7 \mu \mathrm{g} / \mathrm{dL}$, thyrotropin (TSH) $1.3 \mu \mathrm{U} / \mathrm{mL}$, fT3 $5.2 \mathrm{pg} / \mathrm{mL}$, fT4 $0.8 \mathrm{ng} / \mathrm{dL}$; urinary levels were; $17-\mathrm{OHCS} 0.3 \mathrm{mg} /$ day, $17-\mathrm{KS} 0.1 \mathrm{mg} /$ day, free cortisol $3.0 \mu \mathrm{g} /$ day, GH (nighttime and daytime), not detectable. Dynamic hormone tests showed a normal GH response to GRF, but low responses of TSH and adrenocorticotropin (ACTH) to TSH-releasing hormone (TRH) and ACTH-releasing hormone (CRH), respectively. Urinalysis, electrocardiogram, echocardiogram and electroencephalogram were normal. Her IQ was 80 , probably influenced by her uncooperative attitude towards testing.

Soon after admission she showed rapid progressive weight and height gain without any specific treatment, other than an ordinary diet (Fig. 1). All abnormal laboratory findings, became normal along with catch-up growth. Serum GHBP showed a rapid increase to the normal range, followed by rises of serum IGF-I and urinary GH (Fig. 2). She was discharged from hospital five months after admission. However, she showed a weight loss of $3.5 \mathrm{~kg}$ after six months at home. She was re-admitted, this time to Department of Psychiatry, where she showed the same clinical and laboratory findings as in the first admission, and the same recovery of growth.

\section{Discussion}

This patient was diagnosed as having deprivation syndrome based one her growth pattern and laboratory findings. Endogenous

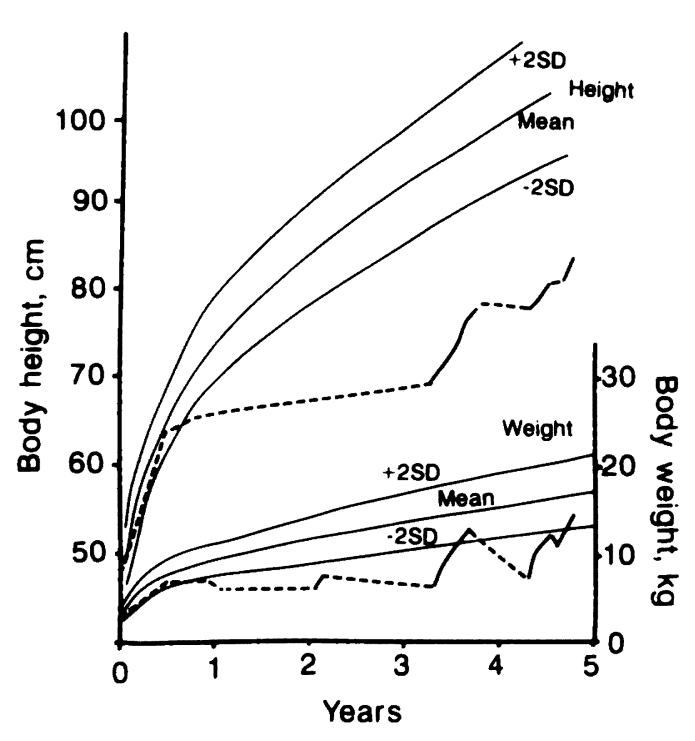

Fig.1 Growth curve for the patient. Solid lines indicate growth during hospitalization, and dotted lines during her stay at home. Body weight and height showed stepwise increases.

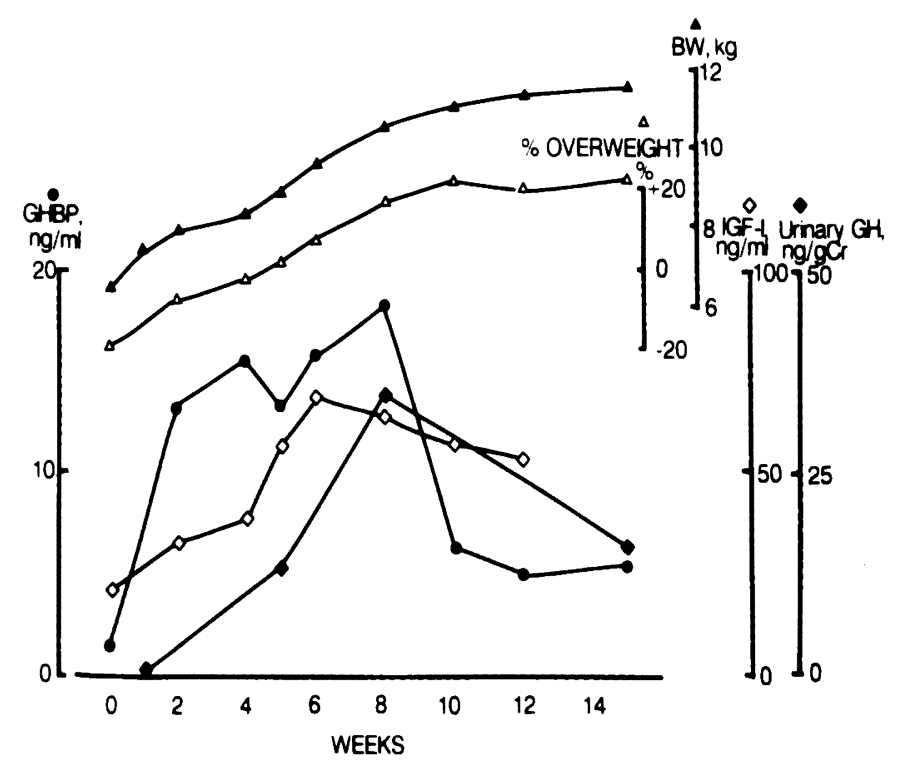

Fig.2 Changes in serum GHBP, IGF-I and urinary GH levels along with nutritional improvement during hospitalization. All these factors rapidly increased with catchup growth. Serum GHBP was measured by ligand-mediated immunofunctional assay (LIFA). The normal range for GHBP in the 3-5 year range is about 4.0 to $70 \mathrm{ng} / \mathrm{mg}$. 
GH secretion was disturbed in this patient, while the response of GH to GRF was conserved. Furthermore, TSH and ACTH responses to TRH and CRH were low, as were $\mathrm{T}_{4}$ and urinary free cortisol excretion. Patients with deprivation syndrome are reported to have GH deficiency (1-3) and sometimes TSH deficiency (2), in contrast to patients with anorexia nervosa who show hypersecretion of GH. The responses of $\mathrm{GH}$ to insulin-induced hypoglycemia were low in these reported cases, while the response to GRF is normal (6). Thus GH deficiency in these patients was probably due to hypothalamic dysfunction. The hormonal findings of our patient also suggest abnormal hypothalamic function.

Serum GHBP levels in our patient were very low on admission and rapidly increased with improvement of nutrition. Low GHBP levels suggest there are fewer GH receptors. In cases with emotional deprivation, GH administration is ineffective in improving the poor growth rate short stature (5). Our findings of few GHBP levels could be an explanation for this observation. Why does serum GHBP decrease? The low GHBP levels in our case cannot be explained by a down regulation by $\mathrm{GH}$ since this case showed GH insufficiency. On the other hand, we observed a highly significant positive correlation between serum GHBP's and the percentage overweight in normal control subjects (7). Therefore, malnutrition itself or mediated by nutritional factors such as insulin might be the cause for low GHBP levels.

Hypothalamic dysfunction is one possible cause of growth failure in deprivation syndrome, while another cause could be tissue resistance to GH due to malnutrition.

\section{References}

1. Suwa S. Deprivation dwarfism. In: Shin-shouniigakutaikei 16 C, Tokyo: Nakayamashoten, 1981: 25-32 (in Japanese).

2. Powell GF, Brasel JA, Raiti S, Blizzard RM. Emotional deprivation and growth retardation simulating idiopathic hypopituitarism II. Endocrinological evaluation of the syndrome. N Engl J Med 1967; 276: 1279.

3. Krieger I, Mellinger RC. Pituitary function in the deprivation syndrome. J Pediatr 1971; 79: 216-25.

4. Powell GF, Hopwood NJ, Barratt RS. Growth hormone studies before and during catch-up growth in a child with emotional deprivation and short stature. J Clin Endocrinol Metab 1973; 37: 674-9.

5. Frasier SD, Rallison ML. Growth retardation and emotional deprivation; Relative resistance to reatment with human growth hormone. J Pediatr 1972; 80: 603-9.

6. Katsumata $N$, Suwa S, Maesaka $H$, Tachibana K, Sawano S, Tanaka T, et al. Growth hormone responses to hpGRF-44 in patients with deprivation syndrome. J Jpn Pediatr Soc 1986; 90: 832-7 (in Japanese).

7. Horikawa R, Tanaka T, Kokai Y, Katsumata $\mathrm{N}$, Nagashima A, Satoh M, et al. Growth hormone-binding protein measurements in normal children and children with short stature using ligandmediated immunofunctional assay. Clin Pediatr Endocrinol 1994; 3 (in press). 